\title{
Factors Affecting Follow-Up Compliance in Patients After Endovascular Aneurysm Repair
}

\author{
Patrick T. Jasinski, MD, Nicos Labropoulos, PhD, Olympia G. Christoforatos, RN, \\ Apostolos K. Tassiopoulos, MD* \\ Division of Vascular and Endovascular Surgery, Stony Brook Medicine, Stony Brook, New York, USA
}

\begin{abstract}
Objective: The purpose of this study was to evaluate potential factors affecting patient non-compliance after endovascular aneurysm repair.

Method: We performed a retrospective review of patients undergoing elective or emergency endovascular repair for thoracic, abdominal aorta, or iliac artery aneurysm at a single institution from November 2007 to March 2014. Compliance to follow-up at 1, 6, and 12 months was assessed. Factors evaluated included patient demographics, size of aneurysm, distance between the patient's residence and outpatient clinic, urgency of surgery, and time of year in which the follow-up visits were scheduled.

Results: During the study period, 205 patients (75\% male and $25 \%$ female) fulfilled the inclusion criteria. One-month mortality was $\mathbf{1 . 1} \%$ for elective procedures and $16.1 \%$ for emergency procedures $(p=0.001)$. Overall mortality at 12 months was $6.3 \%$ and $32.3 \%$ for elective and emergency procedures, respectively ( $p=$ 0.0002). Highest compliance was observed at 1 month, with 184 patients (93\%) attending. A significant decrease was seen at $6(n=102,54 \%)$ and $12(n=89,48 \%)$ months. At the 12-month mark, a larger proportion of minority patients were non-compliant compared with Caucasian patients. Confounders for non-compliance were analyzed using multivariate analysis, and statistical significance was found for widowed marital status ( $p=0.008)$, travel distance $>25$ miles to the outpatient clinic ( $p=0.032)$, and emergency repair of aneurysms $(p=0.022)$.

Conclusion: Despite emphasizing the importance of follow-up after endovascular aortic procedures, almost

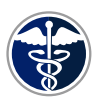

Fax +1 2037853552

E-Mail: aorta@scienceinternational.org http://aorta.scienceinternational.org

\author{
(c) 2017 AORTA \\ Published by Science International Corp. \\ ISSN 2325-4637 \\ Accessible online at: \\ http://aorta.scienceinternational.org
}

half of the treated patients were non-compliant. Our study identified travel distance, marital status, and urgency of surgery as factors that may affect patients' compliance to scheduled follow-up visits.

Copyright @ 2017 Science International Corp.

\section{Key Words}

EVAR - Follow-up - Compliance - Adherence • Non-compliance • Aneurysm repair

\section{Introduction}

Abdominal aortic aneurysm (AAA) is a significant health concern in developed countries with a prevalence of as high as $8 \%$ and an estimated 15,000 aneurysm-related deaths annually in the United States [1, 2]. The prevalence of AAA increases with age in both men and women, with men being more frequently affected. Ruptured AAAs carry a mortality rate of up to $90 \%$ [3], as more than half of AAA patients die on the way to the hospital, and only half of those operated recover from the intervention [4]. The risk of AAA rupture increases with an aneurysm size of $\geq 5.5 \mathrm{~cm}$ for men and $\geq 5.0 \mathrm{~cm}$ for women, above which elective surgery is recommended $[5,6]$. In recent years, endovascular aneurysm repair (EVAR) has become the preferred treatment for AAA with improved perioperative outcomes over open repair [7].

For patients treated with endografts, the Society for Vascular Surgery recommends regular follow-up

* Corresponding Author:

Apostolos K. Tassiopoulos, MD

Division of Vascular and Endovascular Surgery

Stony Brook Medicine

Health Sciences Tower, Level 19, Rm 090, Stony Brook, New York, USA 11794-8191

Tel.: +1 631444 1279; Fax: +1 631444 8824;

E-Mail: apostolos.tassiopoulos@stonybrookmedicine.edu 
imaging with computed tomography (CT) or duplex ultrasonography (DUS) after EVAR due to the risk of late aneurysm rupture resulting from endoleaks, device migration, or structural failure [4, 8-10]. EVAR follow-up imaging is most commonly recommended at 1,6, and 12 months and then yearly thereafter. Few studies have shown the extent of patient non-compliance to surveillance recommendations. Therefore, we evaluated possible factors contributing to non-adherence to recommended surveillance visits among patients undergoing EVAR.

\section{Materials and Methods}

Institutional review board approval and waiver for patient consent were obtained. The Vascular Quality Initiative (VQI) database was utilized to identify eligible patients and capture demographic characteristics and aneurysm anatomical features. Electronic medical records, outpatient medical charts, and diagnostic imaging studies of consecutive patients with aneurysmal disease treated in our institution with EVAR between November 2007 and March 2014 were reviewed. Patients who underwent EVAR for abdominal aorta, thoracic aorta, or iliac artery aneurysms were included. Patients who underwent EVAR $<12$ months prior, open surgery, or repair for dissection and transection were excluded.

\section{Follow-up}

The Society for Vascular Surgery defined a protocol for aneurysm surveillance in 2009. Current guidelines recommend contrast $C T$ imaging at 1 and 12 months during the first year after EVAR, with a 6-month follow-up imaging study only if CT imaging at 1 month identifies an endoleak [4]. We defined compliance as a documented office visit or successfully performed imaging study (CT or DUS) at our institution or another institution. We then divided patients into compliant or non-compliant groups for each interval. Compliance was evaluated at the 1-, 6-, and 12-month post-operative visits. For non-compliant patients, a search was performed in the social security death index (SSDI) database. We assumed that all patients were alive unless a positive result was obtained from the SSDI. The necessity for regular follow-up was discussed with each patient undergoing elective or emergent repair. In addition, we provided information leaflets reinforcing the necessity of follow-up to all patients with a known AAA.

\section{Covariates}

Covariates including age, ethnicity, race, marital status, insurance availability, and distance to facility were analyzed for each follw-up time point for both compliant and non-compliant patients. In the event of missing data in the medical record, patients were excluded from the analysis of the related parameter. Risk factors for the development of AAA included hypertension, hyperlipidemia, history of smoking, coronary artery disease, and family history. Aneurysm size at the time of surgery, season (winter, summer, spring, or autumn), and urgency of surgery (elective or emergency) were also examined. Age groups were defined as $<75$ and $\geq 75$ years, with comparable distributions between groups. Distance to the facility was defined as $\leq 25$ miles or $>25$ miles.

\section{Statistical Analysis}

Analysis of data was performed using IBM SPSS Version 22 (IBM, Armonk, NY). Normally distributed continuous variables (i.e., age at surgery, aneurysm size) were analyzed using independent samples t-tests. Categorical and ordinal variables (i.e., ethnicity, race, marital status, insurance availability, risk factors, season, urgency, age group, and distance to facility) were analyzed using Fischer's exact tests. A multinomial logistic regression model was used to examine potential cofounders. All variables from the previous univariate analyses with $p<0.2$ were included. Non-statistically significant variables for non-compliance were excluded, and an odds ratio (OR) with 95\% confidence interval $(\mathrm{Cl})$ was calculated for the remaining factors. For all comparisons, twotail tests were used. A Kaplan-Meier curve was created to examine compliance to follow-up. Statistical significance was defined as $p<0.05$.

\section{Results}

We identified 205 patients during the study period 
who fulfilled our inclusion criteria. Most patients were male $(n=154)$. Average age was $74.2 \pm 8.1$ years for men and $76.1 \pm 8.1$ years for women. Most patients were Caucasian $(n=192)$ and married $(n=128)$. Median distance to the facility was 12.9 miles (interquartile range (IQR), 7.8-24.3). Elective surgery was performed on 174 patients, and 31 were operated emergently. A significant difference in mortality between patients who underwent elective versus emergency procedures was seen at 1 and 12 months after EVAR. Onemonth mortality was $1.1 \%(n=2)$ after elective procedures and $16.1 \%(n=5)$ after emergency procedures

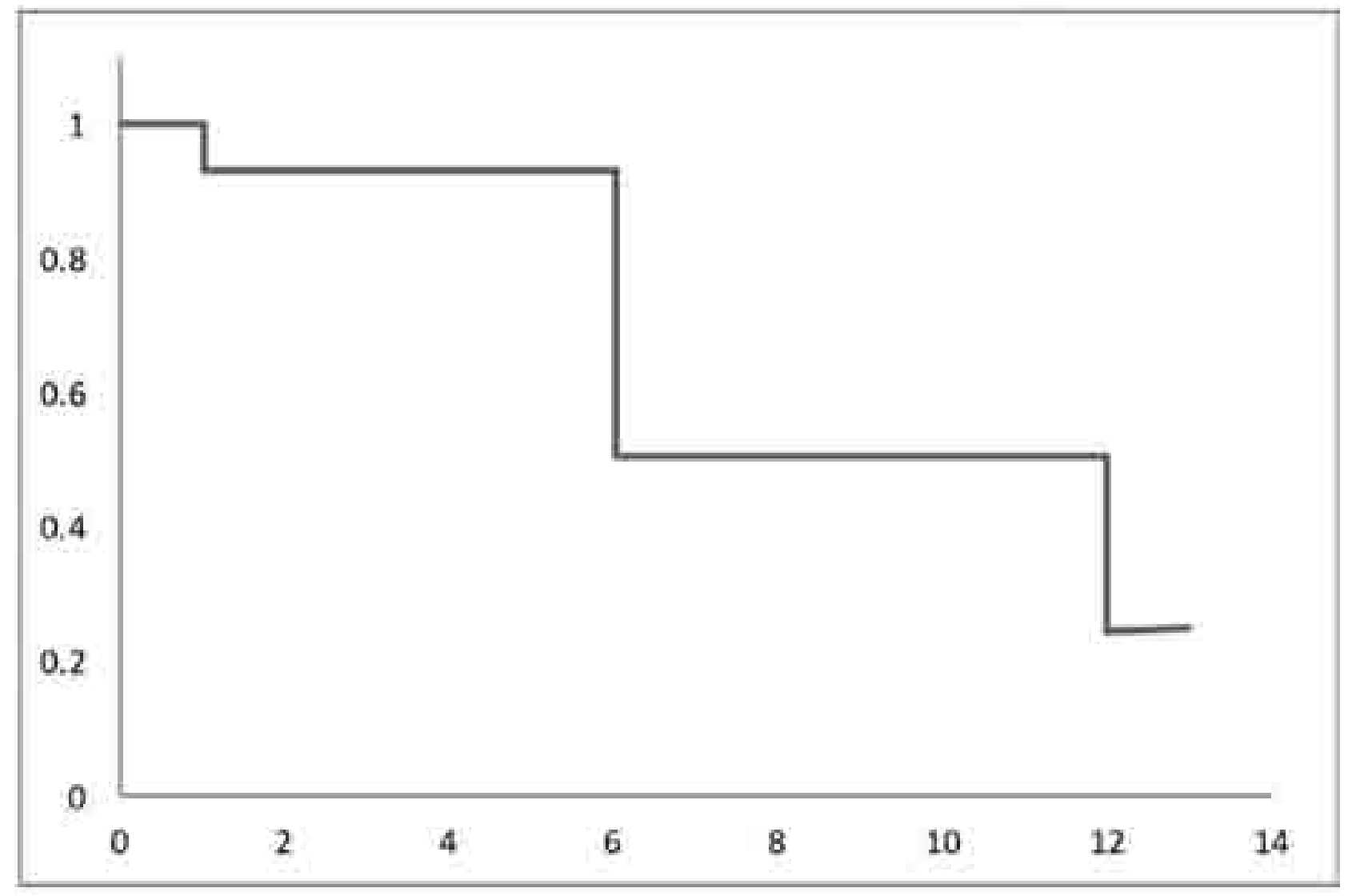

\begin{tabular}{|l|c|c|c|}
\hline & 1 Month & 6 Months & 12 Months \\
\hline Available for follow-up & 198 & 188 & 184 \\
\hline Compliant & $184(93 \%)$ & $102(54 \%)$ & $89(48 \%)$ \\
\hline Non-Compliant & $14(7 \%)$ & $86(46 \%)$ & $95(52 \%)$ \\
\hline
\end{tabular}

Figure 1. Kaplan-Meier survival curve showing post-endovascular aneurysm repair patient compliance to follow-up over a 12-month period. 


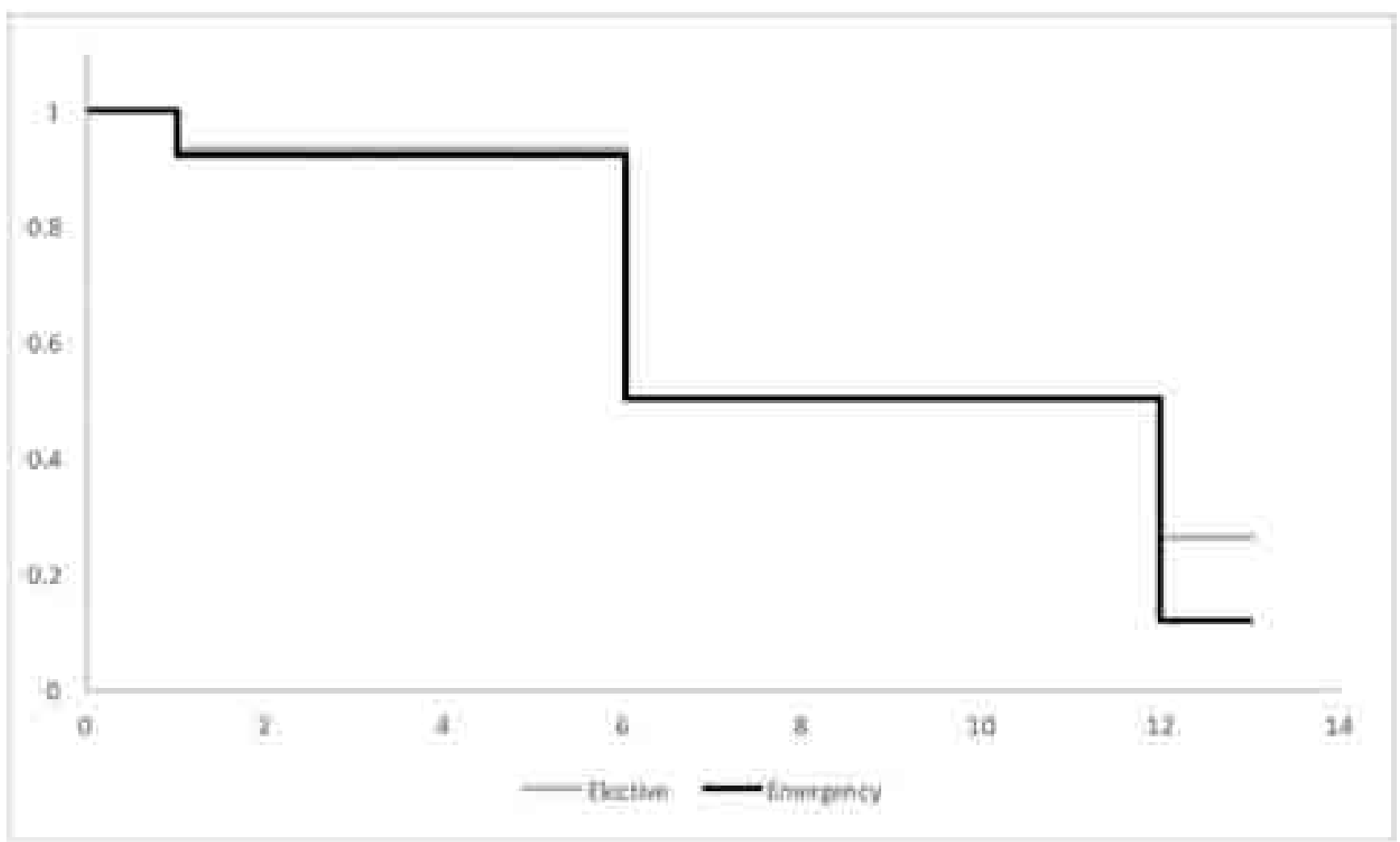

\begin{tabular}{|l|c|c|c|c|c|c|}
\hline & \multicolumn{2}{|c|}{ 1 Month } & \multicolumn{2}{c|}{ 6 Months } & \multicolumn{2}{c|}{12 Months } \\
\hline & Elective & Emergency & Elective & Emergency & Elective & Fmergency \\
\hline $\begin{array}{l}\text { Nvailuble for } \\
\text { follow-up }\end{array}$ & 172 & 26 & 166 & 22 & 163 & 21 \\
\hline Compliant & $160(93 \%)$ & $24(92 \%)$ & $90(54 \%)$ & $12(55 \%)$ & $84(52 \%)$ & $5(24 \%)$ \\
\hline Non-Complant & $12(7 \%)$ & $2(8 \%)$ & $76(46 \%)$ & $10(45 \%)$ & $79(48 \%)$ & $16(76 \%)$ \\
\hline P-Value & & 1 & & & & 02 \\
\hline
\end{tabular}

Figure 2. Patient compliance to follow-up 1, 6, and 12 months after elective or emergency endovascular aneurysm repair $(p=0.02)$.

$(p=0.001)$. Twelve-month mortality was $6.3 \%(n=11)$ and $32.3 \%(n=10)$ after elective and emergent procedures, respectively $(p=0.0002)$.

At 1-month post-EVAR, 198 patients were available for follow-up. Of those, 93\% were compliant and $7 \%$ non-compliant. We found that non-compliance was associated with female gender $(p=0.0245)$, minority race $(p=0.0425)$, widowed marital status $(p=0.0361)$, and lack of health insurance $(p=0.0367)$. Ten patients died between 1 and 6 months after repair, leaving 188 patients available for follow-up visits. Of those, only 102 patients (54\%) were compliant with their scheduled visit at 6 months. Four patients ( 3 compliant and 1 non-compliant at the 6-month follow-up) died between 6 and 12 months after repair, bringing the mortality rate to $10 \%$ at 12 months for the entire 
cohort. At 12-month follow-up, 184 patients were alive and available for follow-up visits, of which 89 (48\%) returned for the annual visit. Most non-compliant patients at 1 month did not return for follow-up at 6 or 12 months and therefore were lost to the entire follow-up schedule.

Figure 1 shows compliance to follow-up at 1,6, and 12 months. Similar to the 1-month follow-up results, non-compliance was more frequently observed in minority $(p=0.0354)$ and widowed $(p=0.0087)$ patients. Married patients were more compliant with follow-up visits $(p=0.044)$. In addition, non-compliance was seen more frequently in patients who had to travel $>25$ miles $(p=0.0378)$ from their residence to the outpatient clinic. Of note, $76.2 \%$ of patients who underwent emergency repair missed their follow-up visit at 12 months.

Figure 2 demonstrates the difference in follow-up compliance between patients undergoing elective versus emergency interventions, demonstrating significant loss to 12-month follow-up for patients who underwent emergency aneurysm repair. Patients with diagnosed hyperlipidemia were more compliant than those without hyperlipidemia. Although not statistically significant, $56.8 \%$ of patients with a history of coronary artery disease were more compliant $(p=0.0718)$ with follow-up visits.

All statistically significant results of multinomial logistic regression analysis are shown in Table 1. Significant confounders for non-compliance were widowed marital status, longer travel distance to the outpatient clinic, no history of hyperlipidemia, and an emergency procedure for symptomatic or ruptured aneurysm. As seen in Table 2, there were no differences in compliance related to hypertension, history of smoking, or family history of AAA. Table 3 shows patient demographics at 1-, 6-, and 12-month follow-up. No significant seasonal variation in adherence to the follow-up schedule was observed. Although compliance was

Table 1. Results from the multinomial logistics regression model analysis. Listed cofounders are significant for non-compliance.

\begin{tabular}{lccc}
\hline Variable & OR & $\mathbf{9 5 \%} \mathbf{C l}$ & P-Value \\
\hline Widowed & 2.94 & $1.323-6.528$ & 0.008 \\
$>25$ miles distance & 2.17 & $1.070-4.392$ & 0.032 \\
Emergency case & 3.40 & $1.191-9.725$ & 0.022 \\
\hline
\end{tabular}

AORTA, October 2017
Table 2. Risk factors for the development of aortic aneurysms and their effect on compliance at 12-months follow-up.

\begin{tabular}{lccc}
\hline Variables & $\begin{array}{c}\text { Compliant } \\
(\mathbf{n}=\mathbf{8 9})\end{array}$ & $\begin{array}{c}\text { Non-Compliant } \\
(\mathbf{n = 9 5 )}\end{array}$ & P-Value \\
\hline Hypertension, No. (\%) & & & \\
Yes & $73(49.7)$ & $74(50.3)$ & 0.582 \\
No & $16(43.2)$ & $21(56.8)$ & \\
Hyperlipidemia, No. (\%) & & & \\
Yes & $59(55.7)$ & $47(44.3)$ & 0.025 \\
No & $30(38.5)$ & $48(61.5)$ & \\
CAD, No. (\%) & & & \\
Yes & $42(56.8)$ & $32(43.2)$ & 0.072 \\
No & $47(42.7)$ & $63(57.3)$ & \\
History of smoking, No. (\%) & & \\
Yes & $57(47.5)$ & $63(52.5)$ & 0.759 \\
No & $32(50.0)$ & $32(50.0)$ & \\
Family History, No. (\%) & & & \\
Yes & $11(57.9)$ & $8(42.1)$ & 0.470 \\
No & $78(47.3)$ & $87(52.7)$ & \\
\hline
\end{tabular}

significantly lower at the 12-month follow-up, we observed substantial improvement in adherence to follow-up recommendations for patients who underwent EVAR after 2011, as can be seen in Figure 3.

\section{Discussion}

EVAR has become the preferred intervention for AAAs in the past two decades [1], with high technical success rates, improved perioperative morbidity and mortality, and similar if not better long-term outcomes compared with open AAA repair. However, the higher risk of late complications in these patients mandates a strict follow-up surveillance protocol. The importance of surveillance needs to be emphasized to patients prior to surgery, as they are potentially at risk for late aneurysm complications including rupture [11]. A few recent studies have reported non-compliance as high as $50 \%$ in patients who underwent EVAR [12-14], similar to what we observed in our patient cohort. These studies, however, did not focus on factors that potentially contribute to non-compliance $[12,14]$. The importance of 
Table 3. Patient demographics and their effect on follow-up compliance at different intervals.

\begin{tabular}{|c|c|c|c|c|c|c|}
\hline \multirow[b]{2}{*}{ Variables } & \multicolumn{3}{|c|}{1 Month } & \multicolumn{3}{|c|}{12 Months } \\
\hline & $\begin{array}{l}\text { Compliant } \\
(\mathrm{n}=184)\end{array}$ & $\begin{array}{c}\text { Non-Compliant } \\
(n=14)\end{array}$ & P-Value & $\begin{array}{l}\text { Compliant } \\
(\mathrm{n}=89)\end{array}$ & $\begin{array}{c}\text { Non-Compliant } \\
(n=95)\end{array}$ & P-Value \\
\hline \multicolumn{7}{|l|}{ Gender, No. (\%) } \\
\hline Male & $144(95.4)$ & $7(4.6)$ & 0.025 & 70 (49.6) & $71(50.4)$ & 0.602 \\
\hline Female & $40(85.1)$ & $7(14.9)$ & & $19(44.2)$ & $24(55.8)$ & \\
\hline Age, mean (SD), y & $74.42(8.04)$ & $75.5(7.48)$ & 0.627 & $74.16(8.82)$ & $74.64(7.42)$ & 0.689 \\
\hline \multicolumn{7}{|l|}{ Age groups, No. (\%) } \\
\hline$<75$ years & $86(92.5)$ & $7(7.5)$ & 1 & $45(51.1)$ & $43(48.9)$ & 0.560 \\
\hline$\geq 75$ years & $98(93.3)$ & $7(6.7)$ & & $44(45.8)$ & $52(54.2)$ & \\
\hline \multicolumn{7}{|l|}{ Race, No. (\%) } \\
\hline Caucasian & $175(94.1)$ & $11(5.9)$ & 0.043 & $88(50.3)$ & $87(49.7)$ & 0.035 \\
\hline Minority & $9(75.0)$ & $3(25.0)$ & & $1(11.1)$ & $8(88.9)$ & \\
\hline \multicolumn{7}{|l|}{ Marital status, No. (\%) } \\
\hline Single & $19(95)$ & $1(5)$ & 1 & $10(52.6)$ & $9(47.4)$ & 0.809 \\
\hline Married & $120(94.5)$ & $7(5.5)$ & 0.262 & $64(53.8)$ & $55(46.2)$ & 0.044 \\
\hline Divorced & $11(100.0)$ & $0(0.0)$ & 1 & $4(44.4)$ & $5(55.6)$ & 1 \\
\hline Widowed & $33(84.6)$ & $6(15.4)$ & 0.036 & $10(27.8)$ & $26(72.2)$ & 0.009 \\
\hline \multicolumn{7}{|l|}{ Insurance, No. (\%) } \\
\hline Yes & $160(94.7)$ & $9(5.3)$ & 0.037 & $79(50.3)$ & $78(49.7)$ & 0.218 \\
\hline No & $24(82.8)$ & $5(17.2)$ & & $10(37.0)$ & $17(63.0)$ & \\
\hline \multicolumn{7}{|l|}{ Distance, No. (\%) } \\
\hline$\leq 25$ miles & $140(93.3)$ & $10(6.7)$ & 0.748 & $74(52.9)$ & $66(47.1)$ & 0.038 \\
\hline$>25$ miles & $44(91.7)$ & $4(8.3)$ & & $15(34.1)$ & $29(65.9)$ & \\
\hline $\begin{array}{l}\text { AAA diameter, cm, } \\
\text { mean (SD) }\end{array}$ & $5.55(1.58)$ & $5.92(1.58)$ & 0.399 & $5.87(1.81)$ & $5.53(2.09)$ & 0.241 \\
\hline \multicolumn{7}{|l|}{ Urgency, No. (\%) } \\
\hline Elective & $160(93.0)$ & $12(7.0)$ & 1 & $84(51.5)$ & $79(48.5)$ & 0.020 \\
\hline Emergency & $24(92.3)$ & $2(7.7)$ & & $5(23.8)$ & $16(76.2)$ & \\
\hline
\end{tabular}

patient adherence to EVAR follow-up is highlighted by Jones et al. [15], who report higher fatal complication rates in patients with incomplete follow-up. Interestingly, more recent publications report that mortality among patients who regularly attend follow-up visits is higher than that among non-compliant patients. Whether these results reflect a difference in comorbidities that trigger more frequent physician encounters in the higher risk group is not clear $[12,13,16]$.

Our institution is the only tertiary care center in Suffolk County, New York and encompasses 1.5 mil- lion individuals [17], with the majority being Caucasian. Suffolk County comprises two-thirds of Long Island with a distance of approximately 85 miles between the east and west borders. Many of our patients, therefore, travel long distances to be seen by physician specialists. Because the median distance traveled by patients in this cohort was 12.9 miles (IQR, 7.8-24.3), for the purpose of comparison we chose a 25 -mile radius to define patients living close versus remote from the point of care. Our results indicate that traveling distance between a patient's residence and the outpatient clinic adversely affects compliance 


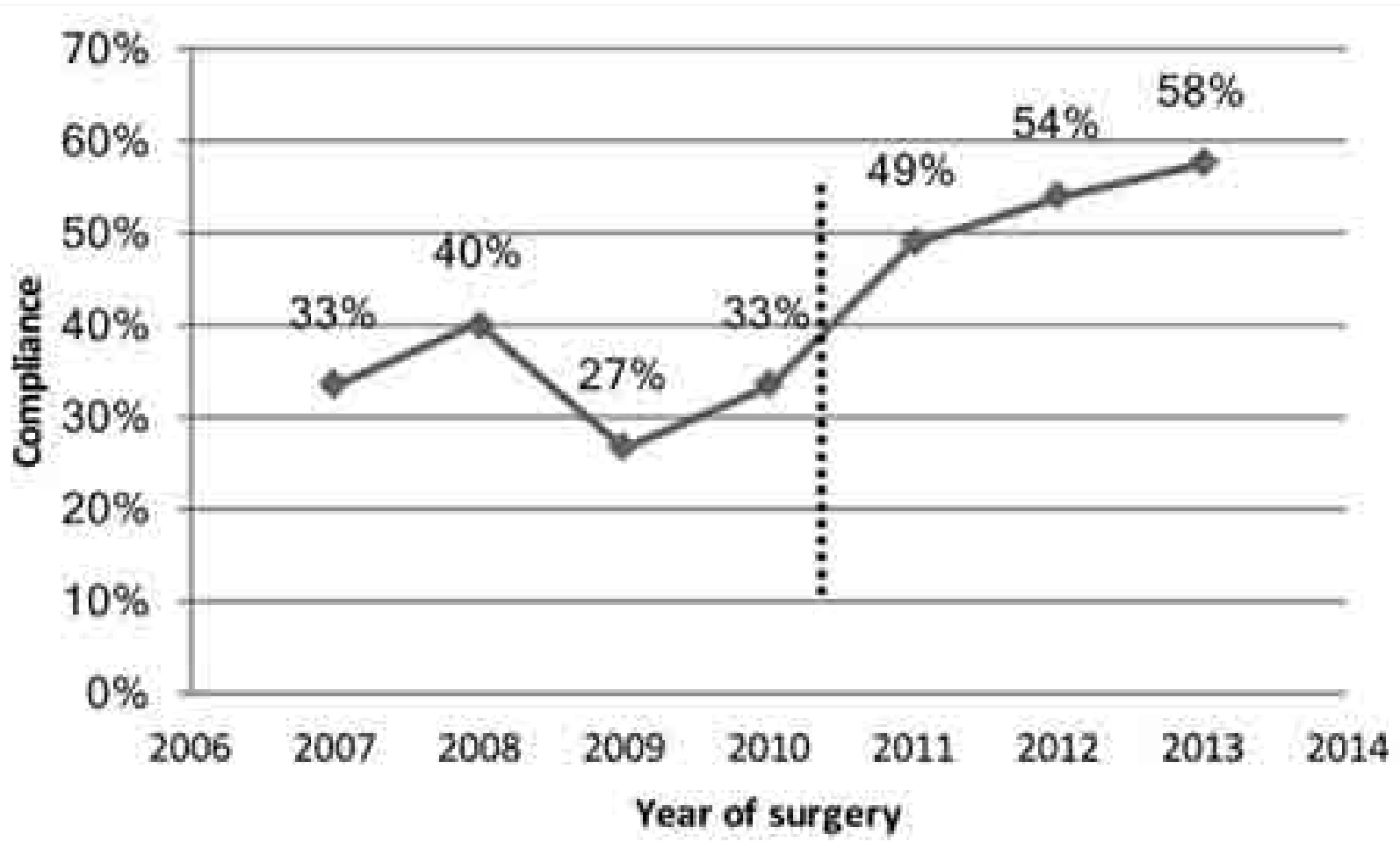

Figure 3. Patient compliance to follow-up 12 months after Endovascular aneurysm repair by year of surgery (2007 to 2013 ). An improvement in compliance was observed from 2011 after utilization of a nurse navigator and Vascular Quality Initiative database (highlighted by the dotted line).

with follow-up visits. Approximately $25 \%$ of patients in our study lived more than 25 miles away from the outpatient physician office. Considering local traffic characteristics in the area, an average $45 \mathrm{~min}$ of driving one-way would be required for these patients to make their appointment, which could represent a challenge to this elderly population. However, this is not supported by other reports [12-14]. For instance, a study performed at the Veterans Affairs Medical Center (VAMC) in Albuquerque, New Mexico examined 136 patients living $\leq 100$ miles or $>100$ miles away from the VAMC [18]. No difference in compliance was found between the two groups, suggesting that a comprehensive electronic records database, an organized and funded patient transportation system, and fewer financial barriers due to VAMC benefits may contribute to adherence to scheduled visits despite the traveling distance. Public transportation to our facility, particularly to outpatient offices, is cum- bersome, and most of our patients have no transportation benefits. This could explain the observed difference in compliance in our study. Another study divided patients into three groups depending on their compliance and found a trend toward a difference among groups based on their average driving distance. These findings are similar to our present observations, suggesting a negative effect of traveling distance on adherence to scheduled follow-ups [13].

Our results also suggest that minority patients tend to be less compliant with follow-up visits. Similar trends of non-adherence have been reported for other conditions [19-21] such as language barriers, higher rate of illiteracy, cultural differences, lower social economic status, and more limited access to outpatient healthcare [22]. These finding are also consistent with a previous study identifying more social work documentation for patients who were eventually lost to follow-up [13]. 
We found less compliance among widowed patients, whereas married patients showed higher compliance. This may reflect support differences at home or perhaps a relative lack of focus on one's daily schedule stemming from psychological factors such as grief of a spouse.

Our analysis also showed that patients who underwent emergency repair due to a symptomatic or ruptured aneurysm were less compliant to follow-up compared with patients who underwent an elective repair. Similar findings were reported by Schanzer et al. [23], who analyzed Medicare beneficiaries and found that patients who undergo elective EVAR are more likely to be compliant. The authors suggest that such patients receive more counseling and achieve a deeper understanding of their condition, resulting in better compliance [23]. Furthermore, patients who are treated in non-elective settings may more often receive care outside of their local health network and therefore be unlikely to return for follow-up [23]. We concur with these explanations and believe that they are also applicable to our patient population.

A large number of senior citizens living in our area are seasonal travelers who usually spend the winter months in southern regions. However, we found no significant differences in compliance based on the season in which follow-up visits were scheduled.

Starting in 2009, a conscious effort has been made by our service to contact EVAR patients who miss scheduled appointments. After we found that multiple patients were not compliant with follow-up, we implemented a nurse navigator who works closely with physicians and residents to coordinate patient care plans. Patients who undergo EVAR are entered into a database, and in the event of a missed scheduled visit, the patient is contacted to re-schedule a new appointment. An upward trend in compliance was noted from 2011, starting at the time of implementation of the nurse navigator in 2010. With the complete change to electronic medical records at our institution in 2014, we created an aneurysm-specific section in the medical chart to track treated and untreated patients with all aneurysm types. Tracked data include aneurysm size, procedure details, diagnostic imaging modality, and the next scheduled appointment. Patient lists are printed every month and identify individuals who have not shown up for their scheduled visit. These patients are then contacted via a phone call to reschedule their appointment. The effectiveness of this system will need to be assessed after its full implementation.

Our study has several limitations including its retrospective design, which limited us to the data documented in medical records and could have contributed to selection bias. Medical records were documented by multiple people with different methods of reporting, whereas more standardized documentation has been noted with electronic medical records. Limiting the study to a short postoperative period may also limit our analysis to only those factors affecting early compliance, whereas a longer follow-up interval could allow analysis of a more complete spectrum of relevant factors. Although we were able to identify deceased patients using the SSDI, we do not know if the deaths were aneurysm-related. Patients or their families were not contacted to determine possible causes of non-compliance or mortality, and we do not know whether non-compliant patients were followed up by another physician, facility, or primary care practitioner. In addition, other investigators have found the SSDI to be inadequate as a sole measure of survival status [24]. Lastly, the small number of patients in our cohort may have increased the chance of a possible type II error.

In conclusion, follow-up surveillance is important for patients who undergo EVAR and should be emphasized to every patient prior to surgery. Usage of tools such as nurse navigators, the VQI database, or a centralized hospital database may improve follow-up compliance, although the effectiveness of the latter option remains to be established. While further studies may be required to develop a clear risk profile for patients undergoing EVAR, the importance of adherence to suggested follow-up standards and alternative treatment options should be discussed in detail with patients and should be considered in the decision-making process for the most suitable treatment modality for each patient.

\section{Conflict of Interest}

The authors have no conflict of interest relevant to this publication.

Comment on this Article or Ask a Question 


\section{References}

1. Dua A, Kuy S, Lee CJ, Upchurch GR Jr, Desai SS. Epidemiology of aortic aneurysm repair in the United States from 2000 to 2010. J Vasc Surg. 2014;59:1512-1517. DOI: 10.1016/j.jvs.2014.01.007

2. Newman $A B$, Arnold $A M$, Burke $G L$, O'Leary DH, Manolio TA. Cardiovascular disease and mortality in older adults with small abdominal aortic aneurysms detected by ultrasonography: the cardiovascular health study. Ann Intern Med. 2001;134:182-190. PMID: 11177330

3. Davidovic L. Treatment strategy for ruptured abdominal aortic aneurysms. Rozhl Chir. 2014;93:357-365. PMID: 25263471

4. Chaikof EL, Brewster DC, Dalman RL, Makaroun MS, Illig KA, Sicard GA, et al. SVS practice guidelines for the care of patients with an abdominal aortic aneurysm: executive summary. J Vasc Surg. 2009;50:880896. DOI: 10.1016/j.jvs.2009.07.001

5. The U.K. Small Aneurysm Trial: design, methods and progress. The UK Small Aneurysm Trial participants. Eur J Vasc Endovasc Surg. 1995;9:42-48. PMID: 7664011

6. Lederle FA, Johnson GR, Wilson SE, Chute $E P$, Hye RJ, Makaroun MS, et al. The aneurysm detection and management study screening program: validation cohort and final results. Aneurysm Detection and Management Veterans Affairs Cooperative Study Investigators. Arch Intern Med. 2000;160:1425-1430. PMID: 10826454

7. Huang Y, Gloviczki P, Oderich GS, Duncan $A A$, Kalra $M$, Fleming MD, et al. Outcome after open and endovascular repairs of abdominal aortic aneurysms in matched cohorts using propensity score modeling. J Vasc Surg. 2015;62:304-311.e2. DOI: 10.1016/j.jvs.2015.02.039

8. Stather PW, Sidloff D, Dattani N, Choke E, Bown MJ, Sayers RD. Systematic review and meta-analysis of the early and late outcomes of open and endovascular repair of abdominal aortic aneurysm. Br J Surg. 2013;100:863872. DOI: 10.1002/bjs.9101

9. Schermerhorn ML, O'Malley AJ, Jhaveri A, Cotterill P, Pomposelli F, Landon BE. Endovascular vs. open repair of abdominal aortic aneurysms in the Medicare population. N Engl J Med. 2008;358:464-474. DOI:

\subsection{6/NEJMoa0707348}

10. Lederle F, Freischlag J, Kyriakides TC, Padberg FT Jr, Matsumura JS, Kohler TR, et al. Outcomes following endovascular vs open repair of abdominal aortic aneurysm: a randomized trial. JAMA. 2009;302:15351542. DOI: $10.1001 /$ jama.2009.1426

11. Mell M, Baker L, Dalman R, Hlatky MA. Gaps in preoperative surveillance and rupture of abdominal aortic aneurysms among Medicare beneficiaries. J Vasc Surg. 2014;59:583588. DOI: 10.1016/j.jvs.2013.09.032

12. Kret MR, Azarbal AF, Mitchell EL, Liem TK, Landry GJ,Moneta GL.Compliance with longterm surveillance recommendations following endovascular aneurysm repair or type $B$ aortic dissection. J Vasc Surg. 2013;58:25-32. DOI: 10.1016/j.jvs.2012.12.046

13. Wu CY, Chen H, Gallagher KA, Eliason JL, Rectenwald JE, Coleman DM. Predictors of compliance with surveillance after endovascular aneurysm repair and comparative survival outcomes. J Vasc Surg. 2015;62:2735. DOI: 10.1016/j.jvs.2015.02.023

14. Godfrey AD, Morbi AH, Nordon IM. Patient compliance with surveillance following elective endovascular aneurysm repair. Cardiovasc Interv Radiol. 2015;38:11301136. DOI: 10.1007/s00270-015-1073-8

15. Jones WB, Taylor SM, Kalbaugh CA, Joels CS, Blackhurst DW, Langan EM 3rd, et al. Lost to follow-up: a potential under-appreciated limitation of endovascular aneurysm repair. J Vasc Surg. 2007;46:434-440. DOI: $10.1016 /$ j.jvs.2007.05.002

16. Waduud MA, Choong WL, Ritchie $M$, Williams C, Yadavali R, Lim S, et al. Endovascular aneurysm repair: is imaging surveillance robust, and does it influence long-term mortality? Cardiovasc Intervent Radiol. 2015;38:33-39. DOI: 10.1007/ s00270-014-0890-5

17. Bureau USC. Suffolk County, New York Population estimates, July 1, 2016, (V2016) [Internet]. Available from: https:// www.census.gov/quickfacts/table/ PST045216/36103

18. Sarangarm D, Knepper J, Marek J, Biggs $\mathrm{KL}$, Robertson $\mathrm{D}$, Langsfeld M. Post-endovascular aneurysm repair patient out- comes and follow-up are not adversely impacted by long travel distance to tertiary vascular surgery centers. Ann Vasc Surg. 2010;24:1075-1081. DOI: 10.1016/j. avsg.2010.05.009

19. Nelson LA, Mulvaney SA, Gebretsadik T, Ho YX, Johnson KB, Osborn CY. Disparities in the use of a mHealth medication adherence promotion intervention for low-income adults with type 2 diabetes. J Am Med Informatics Assoc. 2016;23:12-18. DOI: 10.1093/jamia/ocv082

20. Dickson VV, Knafl GJ, Riegel B. Predictors of medication nonadherence differ among black and white patients with heart failure. Res Nurs Heal. 2015;38:289-300. DOI: 10.1002/nur.21663

21. van den Born BJ, Koopmans RP, Groeneveld $J O$, van Montfrans GA. Ethnic disparities in the incidence, presentation and complications of malignant hypertension. J Hypertens. 2006;24:2299-2304. DOI: 10.1097/01. hjh.0000249710.21146.38

22. Morgenstern LB, Steffen-Batey L, Smith MA, Moye LA. Barriers to acute stroke therapy and stroke prevention in Mexican Americans. Stroke. 2001;32:1360-1364. PMID: 11387499

23. Schanzer A, Messina LM, Ghosh K, Simons JP, Robinson WP 3rd, Aiello FA, et al. Follow-up compliance after endovascular abdominal aortic aneurysm repair in Medicare beneficiaries. J Vasc Surg. 2015;61:1622. DOI: $10.1016 /$ j.jvs.2014.06.006

24. Peterss S, Charilaou P, Ziganshin BA, Elefteriades JA. Assessment of survival in retrospective studies: the Social Security Death Index is not adequate for estimation. J Thorac Cardiovasc Surg. 2017;153:899901. DOI: 10.1016/j.jtcvs.2016.09.014

Cite this article as: Jasinski PT, Labropoulos N, Christoforatos OG, Tassiopoulos AK. Factors Affecting Follow-Up Compliance in Patients After Endovascular Aneurysm Repair. AORTA (Stamford). 2017;5(5):148-156. DOI: https://doi.org/10.12945/j.aorta.2017. 17.046 